ARTICLE

DOI: $10.1038 / s 41467-017-01545-w$

\title{
Atomically dispersed hybrid nickel-iridium sites for photoelectrocatalysis
}

\author{
Chunhua Cui (1) ${ }^{1,2}$, Marc Heggen ${ }^{3}$, Wolf-Dietrich Zabka ${ }^{4}$, Wei Cui (iD) ${ }^{1}$, Jürg Osterwalder ${ }^{4}$, Benjamin Probst ${ }^{1}$ \\ $\&$ Roger Alberto ${ }^{1}$
}

\begin{abstract}
Atomically dispersed supported catalysts can maximize atom efficiency and minimize cost. In spite of much progress in gas-phase catalysis, applying such catalysts in the field of renewable energy coupled with electrochemistry remains a challenge due to their limited durability in electrolyte. Here, we report a robust and atomically dispersed hybrid catalyst formed in situ on a hematite semiconductor support during photoelectrochemical oxygen evolution by electrostatic adsorption of soluble monomeric $\left[\operatorname{lr}(\mathrm{OH})_{6}\right]^{2-}$ coupled to positively charged $\mathrm{NiO}_{x}$ sites. The alkali-stable $\left[\mathrm{Ir}(\mathrm{OH})_{6}\right]^{2-}$ features synergistically enhanced activity toward water oxidation through $\mathrm{NiO}_{x}$ that acts as a "movable bridge" of charge transfer from the hematite surface to the single iridium center. This hybrid catalyst sustains high performance and stability in alkaline electrolyte for $>80 \mathrm{~h}$ of operation. Our findings provide a promising path for soluble catalysts that are weakly and reversibly bound to semiconductorsupported hole-accumulation inorganic materials under catalytic reaction conditions as hybrid active sites for photoelectrocatalysis.
\end{abstract}

\footnotetext{
${ }^{1}$ Department of Chemistry, University of Zürich, Winterthurerstrasse 190, CH-8057 Zürich, Switzerland. ${ }^{2}$ Institute of Fundamental and Frontier Sciences, University of Electronic Science and Technology of China, Chengdu 610054, China. ${ }^{3}$ Ernst Ruska-Centre for Microscopy and Spectroscopy with Electrons, Forschungszentrum Juelich GmbH, Juelich 52425, Germany. ${ }^{4}$ Department of Physics, University of Zürich, Winterthurerstrasse 190, CH-8057 Zürich, Switzerland. Correspondence and requests for materials should be addressed to C.C. (email: chunhua.cui@uestc.edu.cn)
} 
$\mathrm{D}$

uring the past decade, atomically dispersed supported catalysts with $100 \%$ exposure of catalytic sites to reactants have attracted increasing research interest and triggered industrial applications ${ }^{1,2}$, but are rarely exploited for electrocatalysis at solid-liquid interfaces owing to their limited stability $^{3-6}$. One of the harshest reactions in converting solar energy into chemical fuels is the photoelectrochemical oxidation of water to oxygen ${ }^{7}$. This catalytic process needs a bi-component device with a semiconductor photoabsorber that transfers holes to a robust catalyst for oxidizing water ${ }^{8,9}$. However, there has been limited success in immobilizing atomic-scale inorganic materials and/or molecular complexes on cheap semiconductor supports for a long-term reaction, especially in alkaline electrolyte with a reduced energy loss for the oxygen evolution reaction (OER) ${ }^{10,11}$. Precious metal oxides, such as $\mathrm{IrO}_{\mathrm{x}}$, are superior OER catalysts but their cluster-type or monolayer structures are prone to hydroxylation and thus become soluble/detachable in alkaline electrolytes ${ }^{12-16}$. For highly active molecular catalysts grafted on semiconductor supports, the practical operating potential required to drive OER can cleave the organic ligands and lead to the formation of deactivated metal oxide nanoparticles or soluble metal hydroxide species ${ }^{17,18}$. Thus, immobilizing a soluble catalyst directly under OER conditions might present an attractive solution, but some critical issues still remain unresolved ${ }^{19-22}-$ how to bridge the communication between soluble catalyst species and semiconductor surfaces, and how to stabilize the performance and integrity of such a system over an extended time scale.

Here, we report on a hybrid OER catalyst that contains supported sublayer $\mathrm{MO}_{\mathrm{x}}$ sites $(\mathrm{M}=\mathrm{Fe}, \mathrm{Cu}, \mathrm{Co}, \mathrm{Ni}$, and $\mathrm{Ti})$ and soluble monomeric hexahydroxyiridate (IV) $\left[\operatorname{Ir}(\mathrm{OH})_{6}\right]^{2-}$ anions (Ir-anions). As an ideal molecular model, we uncover a close relationship between the hole accumulation capacity of $\mathrm{MO}_{\mathrm{x}}$ and the enhanced activity of Ir-anions. Among the $\mathrm{MO}_{\mathrm{x}}$ sites, the $\mathrm{NiO}_{\mathrm{x}}$ showed the highest capacity of hole accumulation and favorable weak "Fe/Ni-O-Ir" bonds with Ir-anions during OER, allowing the accumulated holes to subsequently transfer to Ir sites for OER. Contrary to the prevailing notion that the redox species in an electrolyte acts as hole scavenger, thus poisoning the $\mathrm{OER}^{23,24}$, we observe that the Ir-anion coupled to hematite supported $\mathrm{NiO}_{\mathrm{x}}\left(\mathrm{H}-\mathrm{NiO}_{\mathrm{x}}\right)$ demonstrates unusual OER activity enhancement with a turnover frequency of $2.4-12.7 \mathrm{~s}^{-1}$ per Ir site at $1.23 V_{\text {RHE }}$ (Supplementary Note 1). This hybrid catalyst demonstrates superior stability in strong alkaline electrolytes (even $4.0 \mathrm{M} \mathrm{NaOH}$ ) for $>80 \mathrm{~h}$. It combines the advantages of soluble molecular catalysts with fully exposed active sites and the benefits of solid-state materials with unique physicochemical properties, bridging the gap between heterogeneous and homogeneous catalysts.

\section{Results}

Catalyst loading. Nanostructured hematite was applied as a support for catalyst loading (Supplementary Fig. 1). In order to avoid the influence of foreign metals on the surface properties, no extrinsic doping was intentionally introduced into the hematite (Supplementary Note 2). The $\mathrm{MO}_{\mathrm{x}}$ was loaded onto the hematite through a facile transient electroreduction of metal cations to metallic sites (Supplementary Fig. 2) (see Methods section). Controlling the charge going through the circuit manipulates the amount of metal atoms loaded onto the surface. For instance, $\mathrm{Ni}$ is electrodeposited at $-1.1 \mathrm{~V}$ vs. $\mathrm{Ag} / \mathrm{AgCl}$ with a charge density of $0.2 \mathrm{mC} \mathrm{cm}^{-2}$ (hereinafter geometric area), which corresponds to $\sim 1.0 \mathrm{nmol} \mathrm{cm}^{-2}$, leading to $\sim 6.2$ atoms per $\mathrm{nm}^{2}$. The spontaneous oxidation of $\mathrm{Ni}$ in air generates $\mathrm{H}-\mathrm{NiO}_{\mathrm{x}}$ (Supplementary Fig. 3). a

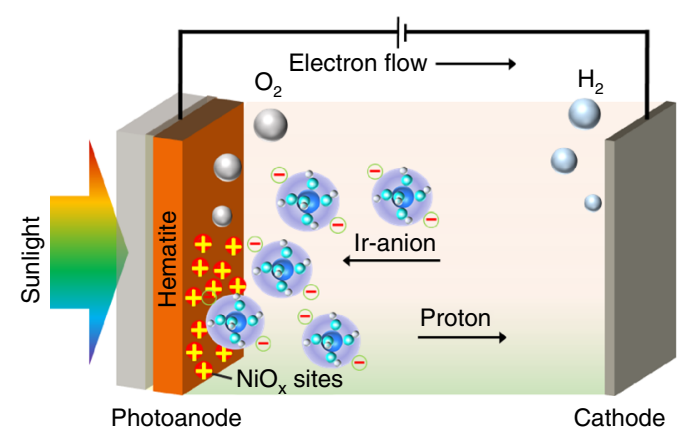

b

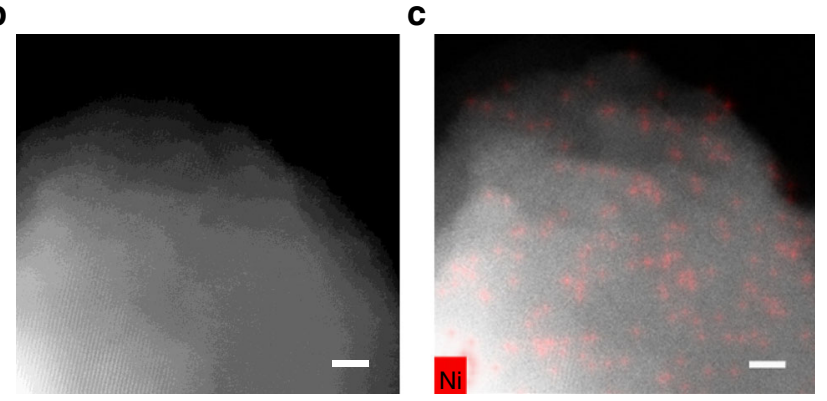

d

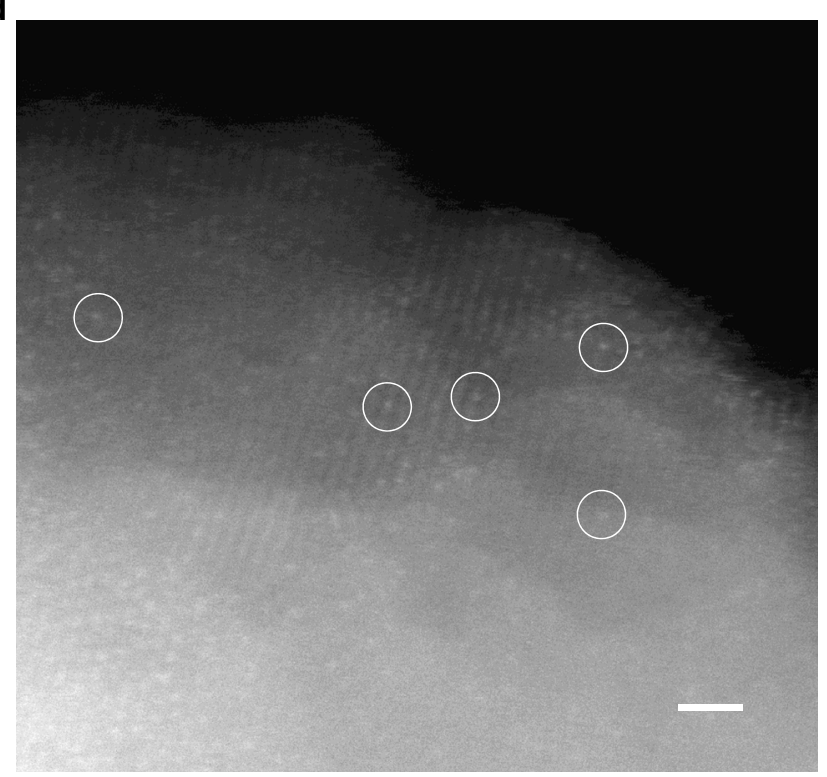

Fig. 1 Synthesis and HAADF STEM images. a Schematic illustration of the preparation process at $1.23 V_{\text {RHE }}$ under AM 1.5 illumination in an electrolyte containing $1.0 \mathrm{M} \mathrm{NaOH}$ and $1.0 \mu \mathrm{M}$ Ir-anion. b High-resolution HAADF STEM image of the hematite-supported catalyst and $\mathbf{c}$ Ni EDX mapping. Scale bar, $2 \mathrm{~nm}$. d Isolated Ir atoms exemplarily indicated by circles are dispersed on the hematite. Scale bar, $1 \mathrm{~nm}$

Unlike in the established methods for molecular catalyst loading, where pre-anchoring is required ${ }^{18}$, the soluble Ir-anion couples to $\mathrm{H}-\mathrm{NiO}_{\mathrm{x}}$ sites in situ during the OER at $1.23 V_{\mathrm{RHE}}$ under AM 1.5 illumination in a photoelectrochemical (PEC) cell (Fig. 1a and Supplementary Fig. 4). The photo-excited holes reach the surface where the positive charges generate an electric field that attracts the negatively charged Ir-anions. When the measured photocurrent plateau is reached, we assume that the Ir-anion approaches an adsorption/desorption equilibrium, after which the loading of Ir on hematite reaches 0.3-1.6 atoms per $\mathrm{nm}^{2}\left(9.5-51.0 \mathrm{n} \mathrm{cm}_{\text {Ir }}^{-2}\right.$ ) (Supplementary Note 1). Note that the 

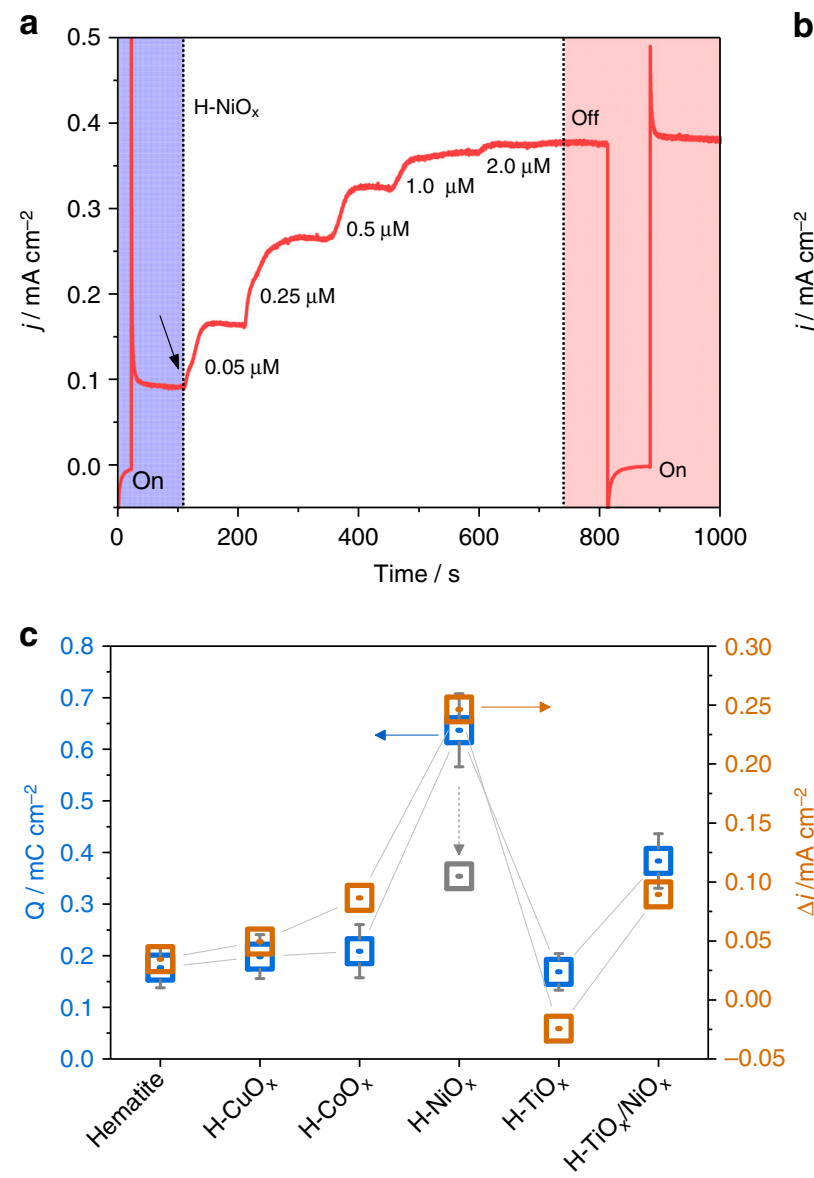

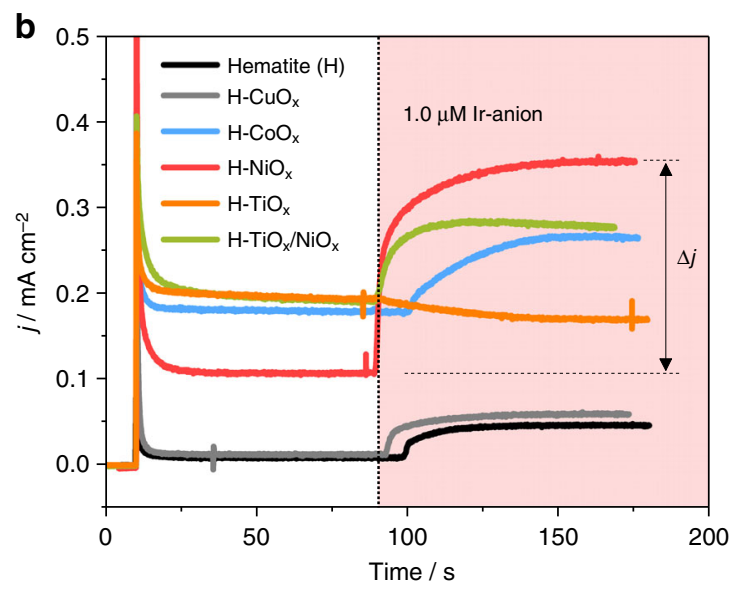

d $\mathrm{H}-\mathrm{TiO}_{\mathrm{x}} / \mathrm{Ir}$-anion $\quad \mathrm{H}-\mathrm{NiO}_{\mathrm{x}} / \mathrm{Ir}$-anion
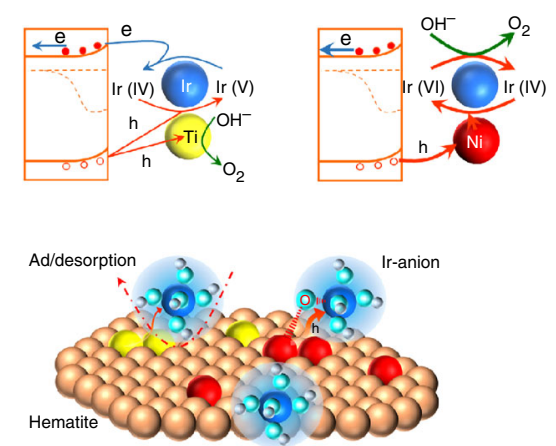

Fig. 2 Photoelectrochemical tests. a OER activity of the $\mathrm{H}-\mathrm{NiO} /$ /Ir-anion with a stepwise increase of Ir-anion solution concentration. b $\mathrm{MO}_{\mathrm{x}}$-modified hematite exhibits significant activity difference $(\Delta j)$ upon dripping the Ir-anion-containing solution. $\mathbf{c}$ The correlation between the hole accumulation capacity of $\mathrm{H}-\mathrm{MO}_{\mathrm{x}}$ before the addition of Ir-anion (Supplementary Fig. 9) and the activity difference $\Delta j$ after the introduction of $1.0 \mu \mathrm{M}$ Ir-anion relative to the Ir-anion-free electrolytes. The gray arrow shows the decreased capacity of $\mathrm{H}-\mathrm{NiO}_{x}$ from 0.64 to $0.35 \mathrm{mC} \mathrm{cm}^{-2}$ (gray square) after the introduction of Ir-anion to the electrolyte. Error bars represent the standard deviation. $\mathbf{d}$ Proposed reaction paths explaining the different roles of $\mathrm{TiO}_{\mathrm{x}}$ and $\mathrm{NiO}_{\mathrm{x}}$ for the OER

non-adsorbed Ir-anion in the electrolyte is not consumed and thus recyclable.

Site structure and catalysis. To identify the atomically dispersed site motifs, the dispersion of the resulting supported $\mathrm{H}-\mathrm{NiO}_{\mathrm{x}} / \mathrm{Ir}$ anion hybrid was characterized by scanning transmission electron microscopy (STEM) in combination with energy-dispersive X-ray spectroscopy (EDX). Individual Ir atoms were imaged using atomic resolution high-angle annular dark field (HAADF) STEM. This technique offers $Z$-contrast conditions, i.e., the image intensity is roughly proportional to $Z^{1.6}-Z^{1.9}$, where $Z$ is the atomic number of the present element (see Methods section). Therefore, the image contrast of $\operatorname{Ir}(Z=77)$ strongly exceeds that of $\mathrm{Fe}(Z=26)$ and $\mathrm{Ni}(Z=28)$, which allows imaging of individual Ir atoms on a selected thin hematite region. Individual Ir atoms (exemplarily indicated by circles) are clearly separate on the hematite surface and show no indication of agglomeration or clustering in Fig. 1d in contrast to the Ir-free images (Supplementary Fig. 5). Figure $1 \mathrm{c}$ is a composite of an HAADF STEM image and a Ni EDX map that shows a homogeneous dispersion of $\mathrm{Ni}$ on the hematite substrate (Fig. 1b).

To assess how the mass transfer of Ir-anion influences the OER activity, two methods were carried out to prepare the Ir-anioncontaining electrolytes (Supplementary Fig. 6). The first test was performed in $10 \mathrm{~mL}$ of homogeneous electrolyte containing $1.0 \mathrm{M}$
$\mathrm{NaOH}$ and $1.0 \mu \mathrm{M}$ Ir-anion $(10 \mathrm{nmol}$ Ir in total). The photocurrent density takes $>1000 \mathrm{~s}$ to reach the plateau. The second method consisted of dripping an identical amount of Iranion solution into the $1.0 \mathrm{M} \mathrm{NaOH}$ at a close distance, about $0.5 \mathrm{~cm}$ away from the $\mathrm{H}-\mathrm{NiO}_{\mathrm{x}}$ electrode. The photocurrent increased suddenly to a maximum value and then started to decrease slowly as the momentary high concentration of Ir-anion close to the $\mathrm{H}-\mathrm{NiO}_{\mathrm{x}}$ electrode gradually diluted to a homogeneous electrolyte. This result indicates that the adsorption/desorption equilibrium is concentration-dependent and that only adsorbed Ir-anions can take part in the OER.

Next, we evaluated the adsorption limitation of Ir-anions to the $\mathrm{H}-\mathrm{NiO}_{\mathrm{x}}$, with a fixed $\mathrm{Ni}$ loading of $\sim 1.0 \mathrm{nmol} \mathrm{cm}{ }^{-2}$. Different concentrations of Ir-anion were chosen to maximize the catalyst's activity. The $\mathrm{H}-\mathrm{NiO}_{\mathrm{x}}$ photoanode in $1.0 \mathrm{M} \mathrm{NaOH}$ at $1.23 V_{\mathrm{RHE}}$ exhibits a steady-state photocurrent density of $0.09 \pm 0.018 \mathrm{~mA}$ $\mathrm{cm}^{-2}$ upon switching on the light (Fig. 2a, blue region). After about $100 \mathrm{~s}, 5 \mu \mathrm{L}$ of pre-prepared Ir-anion solution $(1.0 \mathrm{M} \mathrm{NaOH}$ containing $0.1 \mathrm{mM}$ Ir-anion) was dripped into the $10 \mathrm{~mL} 1.0 \mathrm{M}$ $\mathrm{NaOH}$ electrolyte for the formation of a $0.05 \mu \mathrm{M}$ Ir-anion solution. The photocurrent density increased to $0.17 \mathrm{~mA} \mathrm{~cm}^{-2}$ and then stabilized. A stepwise increase of Ir-anion concentration further enhances the photocurrent density until the Ir-anion concentration reaches about $2.0 \mu \mathrm{M}$ (Fig. 2a, white region). This result is consistent with the variation of the surface Ir loading, where the surface $\mathrm{Ir} / \mathrm{Ni}$ ratio increases slowly above $2.0 \mu \mathrm{M}$ Ir- 

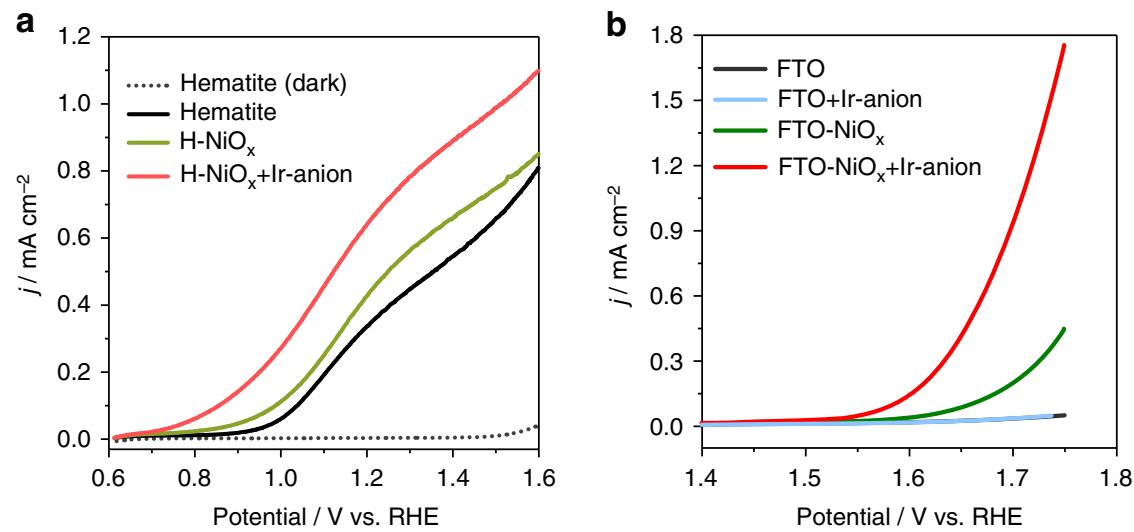

Fig. 3 Catalytic $j-V$ activity. a Linear sweep voltammograms (LSV) on Sn-doped hematite photoelectrodes under AM 1.5 irradiation and b dark FTO electrode at $10 \mathrm{mV} \mathrm{s}^{-1}$ in $1.0 \mathrm{M} \mathrm{NaOH}$

anion concentration (Supplementary Fig. 3). Ir-anion solution of $1.0 \mu \mathrm{M}$ represents a good balance of cost-efficiency and high activity and was therefore selected for the following experiments. A chopped light illumination of the red region of Fig. 2a confirms that the enhanced photocurrent density resulted from light irradiation. This activity enhancement of Ir-anion on $\mathrm{H}-\mathrm{NiO}_{\mathrm{x}}$ relative to bare hematite agrees with the OER polarization curves (Supplementary Fig. 7). A decent activity enhancement was observed after the introduction of $\mathrm{Ni} / \mathrm{Ir}$ hybrid catalyst on Sndoped hematite. A considerable increase of the photocurrent density and a significant negative shift $\sim 200 \mathrm{mV}$ of the onset potential was observed, indicating increased reaction kinetics for water oxidation in Fig. 3a. The enhanced catalytic OER activity was confirmed on a dark F-doped $\mathrm{SnO}_{2}$ (FTO) electrode in Fig. $3 \mathrm{~b}$.

Reaction mechanism. To uncover the interplay between $\mathrm{NiO}_{\mathrm{x}}$ and Ir-anions and to understand the role of $\mathrm{NiO}_{\mathrm{x}}$ sites, we screened a series of $\mathrm{MO}_{\mathrm{x}}$ loadings with different metal ions (Fig. 2b). After dripping of an Ir-anion solution under stirring, an immediate and distinct photocurrent density increase was recorded for $\mathrm{H}-\mathrm{NiO}_{\mathrm{x}}$ but only a slight enhancement was tracked for pristine hematite, $\mathrm{H}-\mathrm{CuO}_{\mathrm{x}}$, and $\mathrm{H}-\mathrm{CoO}_{\mathrm{x}}$ (Fig. 2b, marked with pale color). In contrast, after addition of the Ir-anions, $\mathrm{H}-\mathrm{TiO}_{\mathrm{x}}$ shows a detrimental effect on OER (the surface coverage of $\mathrm{TiO}_{\mathrm{x}}$ on the hematite is shown in Supplementary Fig. 5-this $\mathrm{TiO}_{2}$ sublayer formed by atomic layer deposition (ALD) is amorphous and has electronic defects that allow hole conduction $^{25}$ ). Similar photocurrent decays were previously reported on mesoporous $\mathrm{TiO}_{2}{ }^{23}$ and $\mathrm{W}$-doped $\mathrm{BiVO}_{4}$ photoanodes ${ }^{24}$, respectively. A poisoning mechanism was proposed in which the reversible adsorption/desorption of Ir-anion short-circuits the photoanode redox cycle at the interface between the semiconductor and the electrode FTO back contact ${ }^{23}$.

In the present study, the hematite semiconductor retains the same surface texture and the exposed FTO has no contribution to the activity of Ir-anion (Fig. 3b). The only difference leading to the activity difference is the decorated $\mathrm{MO}_{\mathrm{x}}$ sites on the hematite surfaces, implying a strong dependence of the catalytic behaviors of Ir-anion on the surface properties of $\mathrm{H}-\mathrm{MO}_{\mathrm{x}}$ (Supplementary Fig. 8). The cluster-sized $\mathrm{MO}_{\mathrm{x}}$ sites could be hydroxylated and amorphized under turnover in alkaline solution ${ }^{26,27}$. Notably, although $\mathrm{TiO}_{\mathrm{x}}$ reduces the OER activity of the Ir-anions, the deposition of $\mathrm{NiO}_{\mathrm{x}}$ onto $\mathrm{H}-\mathrm{TiO}_{\mathrm{x}}$ for the formation of an $\mathrm{H}-\mathrm{TiO}_{\mathrm{x}} /$ $\mathrm{NiO}_{x}$ surface significantly increases the photocurrent again (Fig. 2b). This is direct evidence for a synergistic enhancement effect between the $\mathrm{NiO}_{\mathrm{x}}$ and the Ir-anions.
Increased kinetics for OER requires a catalyst with an efficient surface hole density as shown in previous studies ${ }^{28-30}$. To assess the hole accumulation on $\mathrm{MO}_{\mathrm{x}}$ sites, we used a transient photocurrent surface charging-discharging method to evaluate the density of accumulated holes under steady-state conditions

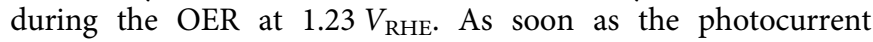
reaches the steady state, the light was switched off to record the cathodic current overshoot, owing to the continuing flux of electrons to the surface sites recombining with remaining holes (Supplementary Fig. 9). The number of the remaining holes describes the hole accumulation capacity of $\mathrm{H}-\mathrm{MO}_{\mathrm{x}}$ (Fig. 2c, open blue square), which is in good agreement with the calculated photocurrent density differences $(\Delta j)$ of the $\mathrm{H}-\mathrm{MO}_{\mathrm{x}}$ photoanodes (Fig. 2c, open yellow square) derived from Fig. 2b. It is evident that the $\mathrm{H}-\mathrm{NiO}_{\mathrm{x}}$ sites exhibit much higher hole accumulation capacity relative to $\mathrm{H}-\mathrm{TiO}_{\mathrm{x}}$, thus promoting the four-electron OER process.

Before the accumulated holes can translocate to the soluble Iranions, the latter have to be bound to the semiconductor surface long enough to allow the photo-excited surface holes to continuously transfer to the Ir sites for catalysis ${ }^{31-33}$. The in situ formation of at least one "Fe/M-O-Ir" bond allows this continuous hole transfer to the $\mathrm{Ir}$ center. $\mathrm{H}-\mathrm{TiO}_{\mathrm{x}}$ is thermodynamically more stable and needs a higher overpotential for the hydroxylation by water as required for the formation of a " $\mathrm{Fe} /$ Ti-O-Ir" bond ${ }^{34,35}$. This makes the modified surface less efficient for transferring four holes to the Ir center for generating one oxygen molecule. Consequently, the Ir-anion is not able to catalyze the OER in the case of $\mathrm{TiO}_{\mathrm{x}}$ but short-circuits the redox cycle, which was reflected in a decrease of the photocurrent (Fig. 2d, left). In contrast, the formation of "Fe/Ni-O-Ir" is favorable, which is consistent with the Ir-Ni binary surface ${ }^{35}$, allowing an instant immobilization of Ir-anion (Fig. 2d, bottom). To roughly quantify the possible ratio between $\mathrm{NiO}_{\mathrm{x}}$ and Iranion, different $\mathrm{Ni}$ loading was applied to $2 \mathrm{~nm}$ thickness of amorphous conformal $\mathrm{TiO}_{\mathrm{x}}$-covered hematite $\left(\mathrm{H}-2 \mathrm{~nm} \mathrm{TiO}_{\mathrm{x}}\right)-$ relieving the influence of pristine hematite $\mathrm{FeO}_{\mathrm{x}}$ sites. The concentration of the Ir-anion was kept at $1.0 \mu \mathrm{M}$. The optimal OER activity was achieved when the amount of $\mathrm{NiO}_{\mathrm{x}}$ was four or more times higher than the immobilized Ir anions based on the HAADF STEM images and X-ray photoelectron spectroscopy (XPS) analysis (see Methods section). Further increasing or decreasing the amount of $\mathrm{NiO}_{\mathrm{x}}$ leads to decreased OER activity (Supplementary Fig. 10). Thus, we propose that one Ir-anion may bridge one or more surface sites and this process depends on the $\mathrm{pH}$ of the solution ${ }^{35,36}$. 

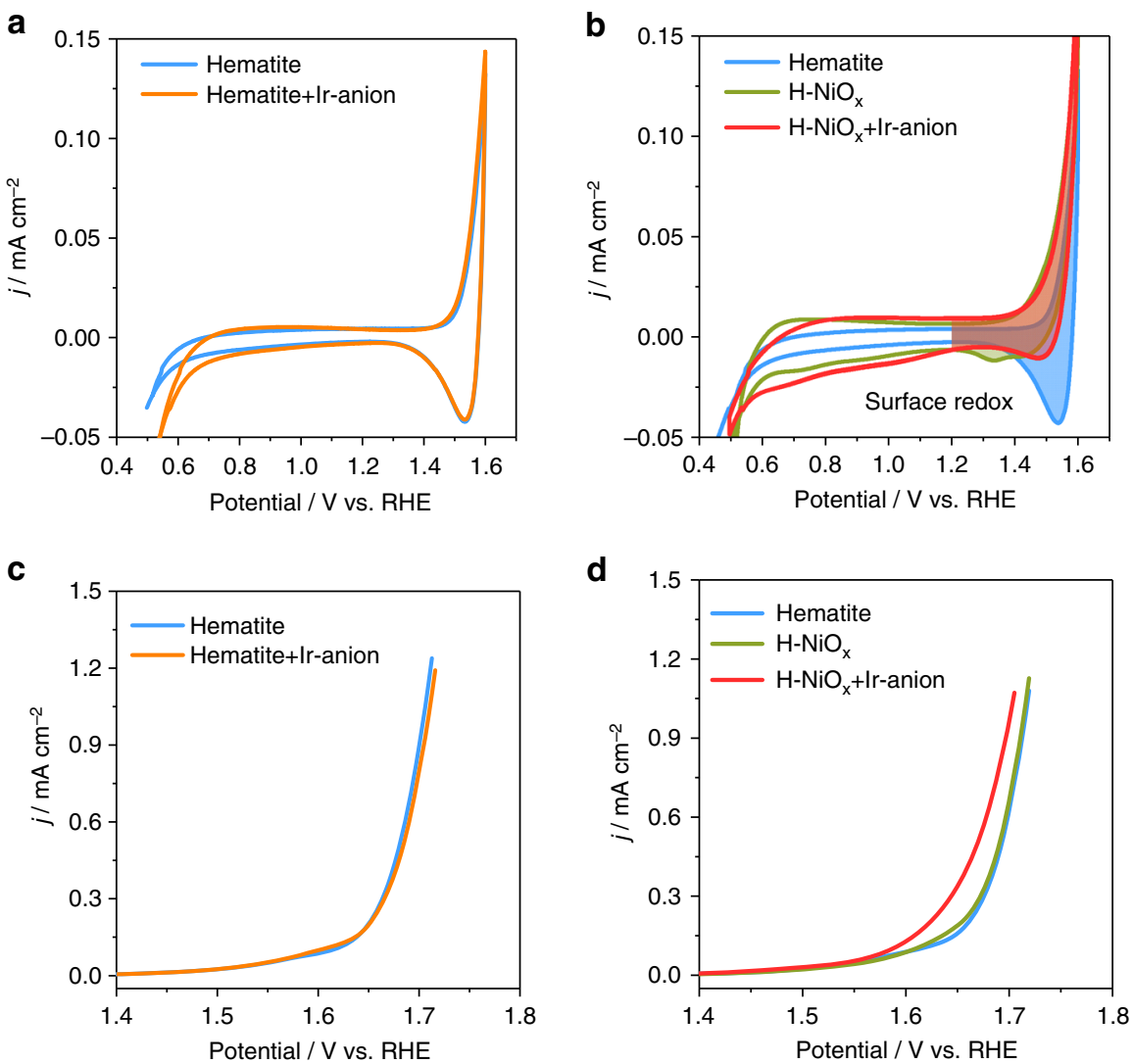

Fig. 4 Charge transfer and activity enhancement. $\mathbf{a}, \mathbf{b}$ Cyclic voltammetry at $50 \mathrm{mV} \mathrm{s}^{-1}$ and $\mathbf{c}$, $\mathbf{d}$ linear sweep voltammetry at $10 \mathrm{mV} \mathrm{s}$ on pristine hematite and $\mathrm{H}-\mathrm{NiO}_{\mathrm{x}}$ in $1.0 \mathrm{M} \mathrm{NaOH}$ in the dark. The concentration of Ir-anion is $1.0 \mu \mathrm{M}$

To evidence the hole transfer from the hematite surface to Iranion through the $\mathrm{NiO}_{\mathrm{x}}$ site, cyclic voltammetry (CV) was performed on hematite and $\mathrm{H}-\mathrm{NiO}_{\mathrm{x}}$ in the dark (Fig. 4). Without $\mathrm{NiO}_{\mathrm{x}}$ loading but in the presence of Ir-anions, the overlay of the $\mathrm{CV}$ curves of hematite and hematite/Ir-anion shows no detectable difference from 0.8 to $1.6 V_{\mathrm{RHE}}$, implying no significant charge transfer between the hematite and the Ir-anions (Figs. 4a and 4c). When $\mathrm{NiO}_{\mathrm{x}}$ was loaded on the hematite, the distinct cathodic peak at $1.55 V_{\mathrm{RHE}}$ of surface iron species was suppressed (Supplementary Fig. 11), substituted by a new cathodic peak at $1.35 V_{\mathrm{RHE}}$, arising from the $\mathrm{Ni}^{\mathrm{III}} / \mathrm{Ni}^{\mathrm{II}}$ redox couple on hematite substrate ${ }^{37}$. Once the Ir-anion was introduced to the electrolyte, the $\mathrm{Ni}$ reduction peak at $1.35 V_{\mathrm{RHE}}$ decreased (Fig. 4b), concomitantly with a highly promoted catalytic activity peak (Fig. 4d), reflecting an efficient charge transfer from $\mathrm{NiO}_{\mathrm{x}}$ to the Ir sites. This result is in agreement with the variation of charge transfer resistance across the catalyst/electrolyte interface evaluated by electrochemical impedance measurements (Supplementary Fig. 12). The pristine hematite did not show any significant resistance change after addition of the Ir-anions, whereas decoration of $\mathrm{NiO}_{\mathrm{x}}$ on hematite decreased the resistance from 25.8 to $6.3 \mathrm{k} \Omega$, and the subsequent addition of Ir-anions further decreased to $4.6 \mathrm{k} \Omega$, implying the favorable charge transfer from $\mathrm{NiO}_{\mathrm{x}}$ to Ir sites. Furthermore, the hole accumulation capacity of $\mathrm{H}-\mathrm{NiO}_{\mathrm{x}}$ decreased from 0.64 to $0.35 \mathrm{mC} \mathrm{cm}^{-2}$ after addition of the Ir-anions, (Fig. 2c, gray square), underlining that the $\mathrm{Ni}$ species transfers charge to the Ir centers ${ }^{29}$. These results confirm the continuous hole transfer from the hematite surface to the Iranions through the $\mathrm{NiO}_{\mathrm{x}}$ sites. As an ideal molecular model, the $\mathrm{NiO}_{\mathrm{x}}$ sites thus serve as "movable bridges" working within the potential region of OER (Fig. 2d, right), thereby improving the OER efficiency.
We verified that the evolved bubbles were indeed $\mathrm{O}_{2}$ using gas chromatography (GC). Based on the GC results and the measured photocurrents, the calculated faradaic yield of $\mathrm{O}_{2}$ is around $94 \%$ (Supplementary Fig. 13). The incident-photon-to-current efficiency (IPCE) was determined to confirm the promotion of hybrid Ir/Ni catalyst relative to the bare hematite (Supplementary Fig. 13). IPCE values match well the band gap of hematite and drop to zero at wavelengths beyond $600 \mathrm{~nm}$.

Stability test. Furthermore, we evaluated the stability of the $\mathrm{H}$ $\mathrm{NiO}_{\mathrm{x}}$ in strong alkaline electrolytes $(1.0$ and $4.0 \mathrm{M} \mathrm{NaOH}$ containing $1.0 \mu \mathrm{M}$ Ir-anion). The $\mathrm{H}-\mathrm{NiO}_{\mathrm{x}}$ demonstrates extremely stable performance in both electrolytes, which makes it a strong candidate as a surface modifier for Ir-anions (Supplementary Fig. 14, gray line). After introducing the Ir-anions, an initial photocurrent increase at the beginning of the operation was attributed to the preferential adsorption of Ir-anions to the $\mathrm{H}$ $\mathrm{NiO}_{\mathrm{x}}$ surface. After this initial phase, the photocurrent density remains constant, indicating the superior stability (Supplementary Fig. 14, red line) over highly loaded $\mathrm{IrO}_{\mathrm{x}}$ nanoparticles ${ }^{15}$. In 4.0 $\mathrm{M} \mathrm{NaOH}$, it takes a longer time period until the photocurrent reaches the plateau, probably due to the slower kinetics for the formation of "Fe/Ni-O-Ir" from the $\mathrm{pH}$-dependent dehydroxylation of Ir-anion ${ }^{36}$.

To assess the stability of the adsorbed/bonded Ir-anions, the $\mathrm{H}$ $\mathrm{NiO}_{\mathrm{x}}$ photoanode and PEC cell were washed several times after $1 \mathrm{~h}$ of operation and freshly prepared $\mathrm{NaOH}$ was added to the PEC cell. The photocurrent density decayed slowly with increasing reaction time (Supplementary Fig. 14), suggesting a slow desorption process during the OER. To measure the reversibility of the Ir-anion adsorption/desorption, Ir-anions 


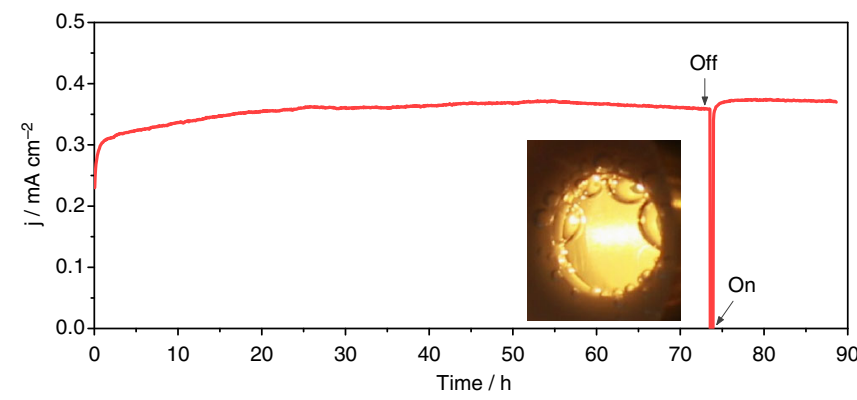

Fig. 5 Stability test on $\mathrm{H}-\mathrm{NiO}_{x}$. The chronopotentiometric curve obtained with the $\mathrm{H}-\mathrm{NiO}_{x}$ photoelectrode in $4.0 \mathrm{M} \mathrm{NaOH}+1.0 \mu \mathrm{M}$ Ir-anion at 1.23 $V_{\text {RHE }}$ under AM 1.5 illumination. A chopped light operation with 20 min interval was performed after $73 \mathrm{~h}$ of continuous stability test. The image of the photoanode window (inset) exhibits a bubble evolution/coverage on the surface of the $\mathrm{Ni} /$ Ir-decorated hematite photoanode

were again supplied to the electrolyte, which restored the photocurrent to the interrupted value, implying a self-healing feature (Supplementary Fig. 14a).

We also assessed the long-term performance stability in $4.0 \mathrm{M}$ $\mathrm{NaOH}$ for $>80 \mathrm{~h}$ of operation (Fig. 5). A continuous stability test of hybrid $\mathrm{Ni} / \mathrm{Ir}$ sites over $73 \mathrm{~h}$ confirmed the high stability. In between, a chopped light operation with a $20 \mathrm{~min}$ interval was performed and the bubbles covering the electrode were removed by mechanically oscillating the electrolyte (inset of Fig. 5). Upon switching on the light, the photocurrent was restored and new bubbles formed gradually. This result corroborates that the hybrid $\mathrm{Ni} / \mathrm{Ir}$ electrocatalyst satisfies the stability requirements of intermittent solar light illumination.

The rational design of a reaction condition-stable catalyst that selectively binds to the semiconductor surface sites under operating conditions increases the performance stability. The developed molecular-anchoring process provides a general photoelectrochemical route for synthesizing homogeneously and atomically dispersed, supported catalysts. Moreover, this study provides a promising path to explore new materials and strategies for combined heterogeneous/homogeneous electrocatalysis systems-an efficient and general strategy to employ other soluble molecular metal complexes ${ }^{19}$ or polyoxometalates ${ }^{38}$ on solid-state inorganic materials-modified semiconductors for solar-driven water splitting.

\section{Methods}

Synthesis of hematite and $\mathbf{H}-\mathbf{M} \mathbf{O}_{\mathbf{x}}$. A nanostructured hematite was applied as a support for catalyst loading. It was prepared by hydrothermal deposition of $\beta$ FeOOH nanorods onto FTO glass (FTO, TEC 15 A $3.0 \mathrm{~mm}$, XOP Física glass company) in an aqueous solution containing $0.15 \mathrm{M} \mathrm{FeCl}_{3} \cdot 6 \mathrm{H}_{2} \mathrm{O}$ (Sigma-Aldrich), and $1.0 \mathrm{M} \mathrm{NaNO}_{3}$ (Sigma-Aldrich) at $95^{\circ} \mathrm{C}$ for $1.5 \mathrm{~h}^{39}$. After the reaction, the asprepared thin films were washed with ethanol/water several times and dried in flowing $\mathrm{N}_{2}$. Then the $\beta$-FeOOH thin films were thermally annealed at $600^{\circ} \mathrm{C}$ for $2 \mathrm{~h}$ in the air leading to the formation of hematite structure. X-ray diffraction and Raman spectra imply the formation of hematite $\mathrm{Fe}_{2} \mathrm{O}_{3}$ (Supplementary Fig. 1). Scanning electron microscopy images show a rough surface that allows for catalyst loading (Supplementary Fig. 1).

The $\mathrm{MO}_{\mathrm{x}}$ loading was achieved through a facile transient electroreduction of metal cations to metallic sites on hematite modified from the reported method ${ }^{40}$. This electrodeposition was implemented in a weak acidic electrolyte $(\mathrm{pH}=4)$, which allows for a control of the amount of atoms deposited ${ }^{40}$, avoiding the spontaneous binding of cations on oxide semiconductor surfaces that happen in neutral and alkaline electrolytes. Controlling the charge going through the circuit manipulates the amount of metal atoms loaded onto the surface. For instance, the $\mathrm{Ni}$ is electroreduced at $-1.1 \mathrm{~V}$ vs. $\mathrm{Ag} / \mathrm{AgCl}$ with a charge density of $0.2 \mathrm{mC} \mathrm{cm}^{-2}$ (geometric area, hereinafter), taking about $0.1 \mathrm{~s}$ for the whole deposition (Supplementary Fig. 2). The amount of deposited $\mathrm{Ni}$ atoms on hematite corresponds to $\sim 1.0 \mathrm{nmol} \mathrm{cm}{ }^{-2}$, leading to $\sim 6.2$ atoms per $\mathrm{nm}^{2}$. After electrodeposition, the spontaneous oxidation of $\mathrm{Ni}$ in air for $\sim 3$ days generates $\mathrm{NiO}_{\mathrm{x}}$ sites. The main XPS peak positions of $\mathrm{Ni}_{2 \mathrm{p}}$ core level are at 873.5 and $856.0 \mathrm{eV}$ (Supplementary Fig. 3); they are attributed to $\mathrm{NiO}_{\mathrm{x}}$ sites. $\mathrm{CuO}_{\mathrm{x}}, \mathrm{CoO}_{\mathrm{x}}$, and $\mathrm{NiO}_{\mathrm{x}}$ sites were equally prepared by this transient electrochemical process. The pristine hematite surface was considered as $\mathrm{FeO}_{\mathrm{x}}$ sites. $\mathrm{TiO}_{\mathrm{x}}$ has been deposited on hematite using an ALD system at $120^{\circ} \mathrm{C}$ (PICSUN R-200). Tetrakis

(dimethylamido)-titanium(IV) $\left(99.999 \%\right.$, Sigma-Aldrich, kept at $85^{\circ} \mathrm{C}$ ) and $\mathrm{H}_{2} \mathrm{O}$ were used as $\mathrm{Ti}$ and $\mathrm{O}$ sources, respectively. Ti precursor was held in the chamber for $1.6 \mathrm{~s}$ under $150 \mathrm{sccm}$ nitrogen flow, followed by a 6-s nitrogen purge. $\mathrm{H}_{2} \mathrm{O}$ was held for $0.1 \mathrm{~s}$ under $200 \mathrm{sccm}$ nitrogen flow, followed by a 6-s nitrogen purge. $\mathrm{TiO}_{x}$ deposition has been calculated to be $0.50 \AA$ per cycle, determined by ellipsometry on a silicon wafer with a native oxide layer.

Synthesis of $\mathbf{H}-\mathbf{M O} \mathbf{O}_{\mathbf{x}} / \mathbf{I r}$-anion. Colorless $\left[\mathrm{Ir}(\mathrm{OH})_{6}\right]^{-2}$ solution $(0.1 \mathrm{mM})$ was prepared in $1.0 \mathrm{M} \mathrm{NaOH}$ by hydrolysis of $\mathrm{K}_{2} \mathrm{IrCl}_{6}{ }^{36}$. The Ir-anions were electrostatically adsorbed to the positively charged $\mathrm{MO}_{\mathrm{x}}$ sites during the photoelectrochemical OER at $1.23 \mathrm{~V}$ vs. reversible hydrogen electrode (RHE) containing Iranions in $\mathrm{NaOH}$ electrolyte under AM 1.5 illumination.

Materials characterizations. Material crystal phases of the $\beta-\mathrm{FeOOH}$ and the hematite were confirmed using X-ray diffraction and Raman. The X-ray diffraction studies were carried out in the range of scanning angle $20-70^{\circ}$ using an X-ray diffractometer with $\mathrm{Cu} \mathrm{K} \alpha$ radiation of wavelength $0.154060 \mathrm{~nm}$ (D8 Discover). A field emission scanning electron microscope (SEM Zeiss Supra 50 VP) was used to observe the surface morphology and estimate the surface texture. XPS was performed with a polychromatic $\mathrm{MgK} \alpha(\mathrm{h} \nu=1253.6 \mathrm{eV})$ and a mono-chromatized AlK $\alpha(\mathrm{h} \nu=1486.6 \mathrm{eV})$ source in a modified Vacuum Generators ESCALAB 220 $\left(p<10^{-9} \mathrm{mbar}\right)^{41}$. The energy scale was calibrated as described in this literature ${ }^{42}$. STEM studies were performed using an FEI Titan ChemiSTEM operated at $200 \mathrm{kV}$ equipped with a Cs-probe corrector and a HAADF detector. This technique offers $Z$-contrast conditions, i.e., the image intensity is roughly proportional to $Z^{1.6}-Z^{1.9}$, where $Z$ is the atomic number of the present element ${ }^{43,44}$. " $Z$-contrast" conditions were achieved using a probe semi-angle of $25 \mathrm{mrad}$ and an inner collection angle of the detector of $70 \mathrm{mrad}$. Compositional maps were obtained with EDX using four large-solid-angle symmetrical Si drift detectors.

Photoelectrochemical characterizations. Photoelectrochemical performance and the related electrochemical measurements were performed by using an SP-300 Potentiostat (Bio-logic). All measurements were made in alkaline electrolytes (1.0 or $4.0 \mathrm{M} \mathrm{NaOH}$ ) in a custom-designed Cappuccino Teflon cell with a quartz window (Supplementary Fig. 4). A standard three-electrode setup was applied by using hematite or $\mathrm{H}-\mathrm{MO}_{\mathrm{x}}$ photoelectrodes as the working electrode and platinum gauze as the counter electrode. All the measured potentials are vs. RHE. A $300 \mathrm{~W}$ Xenon lamp (LOT-QuantumDesign GmbH, Germany) coupled to a filter (AM 1.5) was used to simulate solar light. The light power density was calibrated to $100 \mathrm{~mW}$ $\mathrm{cm}^{-2}$ (AM 1.5) with a Si reference solar cell (LOT-QuantumDesign $\mathrm{GmbH}$, Germany).

Data availability. The data that support the findings of this study are available on reasonable request from the corresponding author (C.C.).

Received: 8 June 2017 Accepted: 26 September 2017

Published online: 07 November 2017

\section{References}

1. Qiao, B. et al. Single-atom catalysis of $\mathrm{CO}$ oxidation using $\mathrm{Pt}_{1} / \mathrm{FeO}_{\mathrm{x}}$. Nat. Chem. 3, 634-641 (2011).

2. Liu, P. et al. Photochemical route for synthesizing atomically dispersed palladium catalysts. Science 352, 797-800 (2016).

3. Zhang, S. et al. Catalysis on singly dispersed bimetallic sites. Nat. Commun. 6, 7938 (2015).

4. Flytzani-Stephanopoulos, M. \& Gates, B. C. Atomically dispersed supported metal catalysts. Annu. Rev. Chem. Biomol. Eng. 3, 545-574 (2012).

5. Nakamura, R. \& Frei, H. Visible light-driven water oxidation by Ir oxide clusters coupled to single $\mathrm{Cr}$ centers in mesoporous silica. J. Am. Chem. Soc. 128, 10668-10669 (2006).

6. Choi, C. H. et al. Tuning selectivity of electrochemical reactions by atomically dispersed platinum catalyst. Nat. Commun. 7, 10922 (2016).

7. Tachibana, Y., Vayssieres, L. \& Durrant, J. R. Artificial photosynthesis for solar water-splitting. Nat. Photonics 6, 511-518 (2012).

8. Montoya, J. H. et al. Materials for solar fuels and chemicals. Nat. Mater. 16, 70-81 (2017).

9. Hunter, B. M., Gray, H. B. \& Müller, A. M. Earth-abundant heterogeneous water oxidation catalysts. Chem. Rev. 116, 14120-14136 (2016).

10. Subbaraman, R. et al. Trends in activity for the water electrolyser reactions on 3d M(Ni,Co,Fe,Mn) hydr(oxy)oxide catalysts. Nat. Mater. 11, 550-557 (2012).

11. Vannucci, A. K. et al. Crossing the divide between homogeneous and heterogeneous catalysis in water oxidation. Proc. Natl Acad. Sci. USA 110, 20918-20922 (2013). 
12. Seitz, L. C. et al. A highly active and stable $\mathrm{IrO}_{\mathrm{x}} / \mathrm{SrIrO}_{3}$ catalyst for the oxygen evolution reaction. Science 353, 1011-1014 (2016).

13. McCrory, C. C. L., Jung, S., Peters, J. C. \& Jaramillo, T. F. Benchmarking heterogeneous electrocatalysts for the oxygen evolution reaction. J. Am. Chem. Soc. 135, 16977-16987 (2013).

14. Nam, Y. S. et al. Biologically templated photocatalytic nanostructures for sustained light-driven water oxidation. Nat. Nano 5, 340-344 (2010).

15. Tilley, S. D., Cornuz, M., Sivula, K. \& Graetzel, M. Light-induced water splitting with hematite: improved nanostructure and iridium oxide catalysis. Angew. Chem. Int. Ed. Engl. 49, 6405-6408 (2010).

16. Oh, H.-S. et al. Electrochemical catalyst-support effects and their stabilizing role for $\mathrm{IrO}_{\mathrm{x}}$ nanoparticle catalysts during the oxygen evolution reaction. J. Am. Chem. Soc. 138, 12552-12563 (2016).

17. Grotjahn, D. B. et al. Evolution of iridium-based molecular catalysts during water oxidation with ceric ammonium nitrate. J. Am. Chem. Soc. 133, 19024-19027 (2011).

18. Duan, L., Tong, L., Xu, Y. \& Sun, L. Visible light-driven water oxidation-from molecular catalysts to photoelectrochemical cells. Energy Environ. Sci. 4, 3296-3313 (2011).

19. Barnett, S. M., Goldberg, K. I. \& Mayer, J. M. A soluble copper-bipyridine water-oxidation electrocatalyst. Nat. Chem. 4, 498-502 (2012).

20. Sheehan, S. W. et al. A molecular catalyst for water oxidation that binds to metal oxide surfaces. Nat. Commun. 6, 6469 (2015).

21. Nakagawa, T., Bjorge, N. S. \& Murray, R. W. Electrogenerated $\operatorname{IrO}_{x}$ nanoparticles as dissolved redox catalysts for water oxidation. J. Am. Chem. Soc. 131, 15578-15579 (2009).

22. Yin, Q. et al. A fast soluble carbon-free molecular water oxidation catalyst based on abundant metals. Science 328, 342-345 (2010).

23. Zhao, Y. et al. Understanding the effect of monomeric Iridium(III/IV) aquo complexes on the photoelectrochemistry of $\mathrm{IrO}_{\mathrm{x}} \cdot \mathrm{nH}_{2} \mathrm{O}$-catalyzed watersplitting systems. J. Am. Chem. Soc. 137, 8749-8757 (2015).

24. Ye, H., Park, H. S. \& Bard, A. J. Screening of electrocatalysts for photoelectrochemical water oxidation on $\mathrm{W}$-doped $\mathrm{BiVO}_{4}$ photocatalysts by scanning electrochemical microscopy. J. Phys. Chem. C 115, 12464-12470 (2011).

25. $\mathrm{Hu}$, S. et al. Amorphous $\mathrm{TiO}_{2}$ coatings stabilize $\mathrm{Si}$, GaAs, and GaP photoanodes for efficient water oxidation. Science 344, 1005-1009 (2014)

26. May, K. J. et al. Influence of oxygen evolution during water oxidation on the surface of perovskite oxide catalysts. J. Phys. Chem. Lett. 3, 3264-3270 (2012).

27. Bergmann A., et al. Reversible amorphization and the catalytically active state of crystalline $\mathrm{Co}_{3} \mathrm{O}_{4}$ during oxygen evolution. Nat. Commun. 6, 8625 (2015).

28. Le Formal, F. et al. Rate law analysis of water oxidation on a hematite surface. J. Am. Chem. Soc. 137, 6629-6637 (2015).

29. Wang, Z. et al. Synergetic effect of conjugated $\mathrm{Ni}(\mathrm{OH})_{2} / \mathrm{IrO}_{2}$ cocatalyst on titanium-doped hematite photoanode for solar water splitting. J. Phys. Chem. C 119, 19607-19612 (2015).

30. Lin, F. \& Boettcher, S. W. Adaptive semiconductor/electrocatalyst junctions in water-splitting photoanodes. Nat. Mater. 13, 81-86 (2014).

31. Zhang, C. et al. A synthetic $\mathrm{Mn}_{4} \mathrm{Ca}$-cluster mimicking the oxygen-evolving center of photosynthesis. Science 348, 690-693 (2015)

32. Materna, K. L. et al. Heterogenized iridium water-oxidation catalyst from a silatrane precursor. ACS Catal. 6, 5371-5377 (2016).

33. Gambardella, A. A., Feldberg, S. W. \& Murray, R. W. Electron transfer dynamics of iridium oxide nanoparticles attached to electrodes by selfassembled monolayers. J. Am. Chem. Soc. 134, 5774-5777 (2012).

34. Li, Y.-F., Liu, Z.-P., Liu, L. \& Gao, W. Mechanism and activity of photocatalytic oxygen evolution on titania anatase in aqueous surroundings. J. Am. Chem. Soc. 132, 13008-13015 (2010).

35. Reier, T. et al. Molecular insight in structure and activity of highly efficient, low-Ir Ir-Ni oxide catalysts for electrochemical water splitting (OER). J. Am. Chem. Soc. 137, 13031-13040 (2015).

36. Zhao, Y., Vargas-Barbosa, N. M., Hernandez-Pagan, E. A. \& Mallouk, T. E. Anodic deposition of colloidal iridium oxide thin films from hexahydroxyiridate(IV) solutions. Small 7, 2087-2093 (2011).
37. Trotochaud, L., Young, S. L., Ranney, J. K. \& Boettcher, S. W. Nickel-iron oxyhydroxide oxygen-evolution electrocatalysts: the role of intentional and incidental iron incorporation. J. Am. Chem. Soc. 136, 6744-6753 (2014).

38. Toma, F. M. et al. Efficient water oxidation at carbon nanotubepolyoxometalate electrocatalytic interfaces. Nat. Chem. 2, 826-831 (2010).

39. Vayssieres, L., Beermann, N., Lindquist, S. E. \& Hagfeldt, A. Controlled aqueous chemical growth of oriented three-dimensional crystalline nanorod arrays: application to iron(III) oxides. Chem. Mater. 13, 233-235 (2001).

40. Hill, J. C., Landers, A. T. \& Switzer, J. A. An electrodeposited inhomogeneous metal-insulator-semiconductor junction for efficient photoelectrochemical water oxidation. Nat. Mater. 14, 1150-1155 (2015).

41. Greber, T. et al. A photoelectron spectrometer for k-space mapping above the Fermi level. Rev. Sci. Instrum. 68, 4549-4554 (1997).

42. Seah, M. P. Summary of ISO/TC 201 Standard: VII ISO 15472: 2001-surface chemical analysis-X-ray photoelectron spectrometers-calibration of energy scales. Surf. Interface Anal. 31, 721-723 (2001).

43. Hartel, P., Rose, H. \& Dinges, C. Conditions and reasons for incoherent imaging in STEM. Ultramicroscopy 63, 93-114 (1996).

44. Nellist, P. D. \& Pennycook, S. J. Incoherent imaging using dynamically scattered coherent electrons. Ultramicroscopy 78, 111-124 (1999).

\section{Acknowledgements}

C.C. acknowledges financial support from the University of Zurich, the University Research Priority Program (URPP) "Light to Chemical Energy Conversion" (LightChEC). SEM imaging was performed with the support of the Center for Microscopy and Image Analysis, University of Zurich. C.C. acknowledges Professor C. Li from DICP for valuable discussions during his visit in Zurich. We thank Professor D. Tilley, R. Prabhakar, R. Wick, Dr. H. Liu for sample preparation and characterization assistance, and Dr. C. Richmond for valuable discussions.

\section{Author contributions}

C.C. conceived and designed the experiments, carried out the experiments, analyzed the results, and wrote the manuscript. M.H. performed the HAADF STEM and EDX measurements and analyzed the results. W.-D.Z. and J.O. contribute to the XPS and element quantification. W.C., B.P., and R.A. contributed to the characterizations and analysis. All authors commented on the manuscript.

\section{Additional information}

Supplementary Information accompanies this paper at doi:10.1038/s41467-017-01545-w.

Competing interests: The authors declare no competing financial interests.

Reprints and permission information is available online at http://npg.nature.com/ reprintsandpermissions/

Publisher's note: Springer Nature remains neutral with regard to jurisdictional claims in published maps and institutional affiliations.

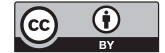

Open Access This article is licensed under a Creative Commons Attribution 4.0 International License, which permits use, sharing, adaptation, distribution and reproduction in any medium or format, as long as you give appropriate credit to the original author(s) and the source, provide a link to the Creative Commons license, and indicate if changes were made. The images or other third party material in this article are included in the article's Creative Commons license, unless indicated otherwise in a credit line to the material. If material is not included in the article's Creative Commons license and your intended use is not permitted by statutory regulation or exceeds the permitted use, you will need to obtain permission directly from the copyright holder. To view a copy of this license, visit http://creativecommons.org/ licenses/by/4.0/

(C) The Author(s) 2017 